\title{
ESTUDOS SOBRE A INTERDISCIPLINARIDADE: ritual da ciência ou ciência do ritual?
}

\section{Fernando César de Souza*}

\section{RESUMO}

\begin{abstract}
Há tempos a interdisciplinaridade aparece como uma força motriz das pesquisas científicas, das práticas pedagógicas ou corporativas, bem como estampa os títulos de graduações ou pós-graduações no Brasil e no mundo, o que a transforma num conceito com múltiplos sentidos e significados para além das suas próprias definições. Aliás, definir a interdisciplinaridade pode empobrecer sua função de abertura frente ao conhecimento, à ciência e a informação numa sociedade que tem a complexidade como identidade-mor. Ou ainda dissecá-la numa frase ou paradigma que o deixaria do tamanho laboratorial permitindo aos pesquisadores sua manipulação em variáveis e tubos de ensaios. Por isso que o presente trabalho tem o formato de estudo que compreende as multiplicidades históricas que fazem da Interdisciplinaridade um ato do cuidado e uma experiência da escuta entre as pessoas e o mundo numa educação-próxima-denós, quase familiar. Como resultado, são apresentados alguns temas comuns legitimados nas formações com os profissionais da Educação e da Saúde realizadas entre os períodos de 2014 a 2016, na cidade de São Paulo, como um exercício da autonomia entre $\circ$ fazer e $\circ$ sentir pedagógicos no desenvolvimento humano para o bem-estar coletivo e colaborativo.
\end{abstract}

Palavras-chave: complexidade; ritual da ciência; ciência do ritual; interdisciplinaridade; escuta sensível.

\footnotetext{
* Doutor em Educação pela Universidade de São Paulo, Brasil. Coordenador Educacional do Serviço Nacional de Aprendizagem Comercial em São Paulo, Brasil. Pesquisador do Grupo de Estudos e Pesquisas em Interdisciplinaridade.

E-mail: Fernando.csouza@sp.senac.br
}

\section{INTRODUÇÃO '}

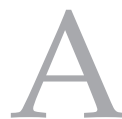

o decidir pela profissão, uma pessoa tende a percorrer as trilhas formativas existentes no sistema educacional divulgadas pela cultura escolar e/ou mercadológica. Assim, ela escolhe um campo do saber e adentra num local construído epistemologicamente com os conteúdos característicos e 'compactados' para servi-la. Inserida no sistema, ela passará por conteúdos sistematicamente organizados para facilitar sua

\footnotetext{
I O presente texto é um desdobramento da comunicação intitulada 'A Interdisciplinaridade na Ciência da Informação' apresentada no XVII Encontro Nacional de Pesquisa em Ciência da Informação - ENANCIB 2016, no Colóquio do Grupo de Trabalho I: Estudos Históricos e Epistemológicos da Ciência da Informação, em novembro de 2016.
}

carreira profissional, e todas as informações das disciplinas escolhidas estarão dispostas para que aprenda com eficácia os instrumentos para a alta performance. Aos poucos, essa pessoa vai se adaptando ao cumprimento desses rituais com foco no êxito, num oásis de funcionalidade e produtividade, pelo menos é o que é veiculado por alguns meios comunicacionais.

Esse breve fluxo da educação formal exemplifica o modelo estandardizado desde o início da Revolução Industrial culminando num cenário de mais de 2.000 disciplinas na passagem do século XX para o XXI, em comparação as sete disciplinas mestras no fim da Idade Média. Então, forjados nesse servir e convictos das verdades que cercam cada campo disciplinar, muitas vezes sentimo-nos distantes 
das potencialidades criativas que 'habitam' nas fronteiras do conhecimento, pois "uma fronteira não é o ponto onde algo termina, mas, como os gregos reconheceram, a fronteira é o ponto a partir do qual algo começa a se fazer presente". (M. Heidegger in Bhabha, H.K, 2001).

Entende-se que o centro de cada disciplina está carregado de singularidades próprias de cada profissão ou confraria, o que permite ao profissional certa segurança epistemológica ou relacional como falar a mesma linguagem, se comportar ou reagir aos 'ataques' estrangeiros. Somente quando a pessoa se permite explorar as margens do seu campo disciplinar e salta 'além-mar' pelas lentes da interdisciplinaridade, é que se arriscará numa aventura de incertezas e incompletudes. O mesmo acontece com o currículo escolar que não promove as interrelações dialógicas com outras culturas, causando uma "cegueira diante do conhecimento", segundo Edgar Morin, filósofo francês que estuda a Teoria da Complexidade.

Daí a importância de (re) aprender sobre a multiplicidade de sentidos advindas do pensamento interdisciplinar ao longo da vida com o objetivo de expandir nossa consciência cidadã rumo ao cuidado de si, do outro e do mundo. O cuidado adquire um status social quando é apresentado como uma atitude promotora da interação entre as pessoas, os processos, as informações e as ciências, pois o pensamento interdisciplinar surge de "uma nova atitude diante da questão do conhecimento, de abertura à compreensão dos aspectos ocultos do ato de aprender e dos aparentemente expressos, colocando-os em questão". (FAZENDA, 2002, p.11).

Parte-se então da interdisciplinaridade que não desconsidera a disciplina, e não sufoca sua história construída paulatinamente durante séculos de transmissões orais, escritas, vividas, em detrimento de algo dito inovador ou tecnológico. Compreendida como fundamento científico, a disciplina funciona como um instrumento de organização do pensamento ou de 'adestramento' dos saberes em espaços organizados para ensinar e aprender, não exclusivos aos ambientes escolares.

Se é sabido que as pessoas passam pela escolarização como premissa de socialização desde a infância (cada vez mais precoce), então que essa passagem as apoie em seu desenvolvimento e em suas descobertas de autorias e responsabilidades. A disciplina também é entendida:

Como ramo do saber: a Matemática, a Física, a Biologia, a Sociologia ou a Psicologia ramos do saber ou, melhor, alguns desses grandes ramos. Depois, temos as subdisciplinas e assim sucessivamente. Disciplina como componente curricular: História, Ciências, Natureza, Cristalografia, Química Inorgânica, etc. Finalmente, disciplina como conjunto de normas ou leis que regulam uma determinada atividade ou o comportamento de um determinado grupo: a disciplina militar, a disciplina automobilística ou a disciplina escolar, etc. (POMBO, 2003, p.I2, grifo nosso)

Nessa sistematização disciplinar, cabe evidenciar os rituais que as ciências se constituíram sob demandas sociais ou políticas na oferta da educação com propósitos comuns de 'controles e hierarquizações', independentemente de qual cultura falamos. Aqui a Scientia pode ser vista como um 'produto' dos mecanismos políticos e ideológicos que estimularam os programas educativos ou as metas governamentais a serem cumpridas em curto espaço de tempo, num ritual desagregador apresentado, onde

\begin{abstract}
A ciência é hoje uma enorme instituição, com diferentes comunidades competitivas entre si, de costas voltadas umas para as outras, grupos rivais que lutam para arranjar espaço para o seu trabalho, que competem por subsídios, que estabelecem entre si um regime de concorrência completamente avesso àquilo que era $\mathrm{o}$ ideal científico da comunicação universal. (POMBO, 2004, p. 17)
\end{abstract}

No entendimento do ideal científico da comunicação universal, caberia uma proposta metodológica interdisciplinar que aproximaria a ciência, a informação e a comunicação no restabelecimento do diálogo, da escuta e do 'conhecimento pertinente', segundo Edgar Morin. Distantes do pensamento de Morin, vê-se que a interdisciplinaridade aparece inexpressiva e repetitiva para alguns pesquisadores que se ancoram somente na sua definição ou tentam analisar seus fragmentos, haja vista o excesso de especialização dos saberes denunciados desde a metade do século XIX. Os claustros científicos 
acabam protegendo seus iguais, mantendo a mesma linguagem ou 'habitus corporativistas', desconsiderando as vizinhanças epistemológicas ou sociais, filósofo brasileiro e pesquisador das ciências, que anunciava que

A ciência é a consciência do mundo.
A doença do mundo moderno
corresponde a um fracasso, a uma
demissão do saber. Semelhando
propósito pode surpreender, se
pensarmos na multidão de 'sábios'
ou pretensos sábios que povoam as
universidades, os laboratórios, os
institutos de pesquisa em toda a face da
Terra. (JAPIASSU, 1976, p. II)

Se a escola é um espaço reconhecido socialmente para a sistematização do processo do conhecer, há que se esperar muito mais na abertura da crítica e da autonomia dos seus usuários. Ao pensar nas ciências da educação sob a abordagem interdisciplinar em três atos - cuidar de si, do outro e do mundo - pode-se, minimamente, compreender os choques entre as culturas dos alunos com as culturas escolares, sendo a segunda comumente mais rígida e que aponta para o homem ideal, dentro da concepção iluminista do século XVII.

De Platão (400 a.C), passando por Comenius (século XVI), ou Celestín Freinet (século XX), ou Anísio Teixeira (século XX), ou Paulo Freire (século XX), entre tantos, é possível compreender os três atos do cuidado que sustentam as próprias histórias de vidas, envolta de tradições passadas de gerações a gerações. Aos pesquisadores em Ciências, o desafio de recriar suas investigações para além da razão que tende às fixações blocadas e episódicas da realidade social, fechadas em verdades não questionadas e não reposicionadas. Os cientistas são demandados à uma revisão do jeito de fazer pesquisas, numa arqueologia da informação e da comunicação, interdisciplinar e intencional, onde o ato do cuidado e a experiência da escuta tornam-se premissas atitudinais na expansão do conhecimento, pois "A interdisciplinaridade não é apenas uma disciplina resistente, da forma como minha geração tratava a resistência à autoridade. Há várias boas razões para ser interdisciplinar, mas todas dependem da manutenção de uma certa disciplina" (CALHOUN, 2012, p. 299).

Nesse processo de conhecer, o aprendizado horizontal possibilitaria ao mestre e ao aprendiz a inversão dos seus papéis educativos no decorrer das jornadas formativas na ruptura dos paradigmas da arte do pensar. Então se a escola ou o local de aprender, a scholé para os gregos, promovesse o ócio filosófico, uma nova competência individual e responsável se instalaria. Um ócio para o pensar que renovaria o espírito, permitiria a prática criativa e autônoma na conscientização humana para a transformação do seu meio. Alunos vistos em suas potencialidades, as escolas vistas como espaços de práticas interdisciplinares, as sociedades vistas como lugares de boa convivência e bemestar coletivos, exemplificam o efeito simbiótico entre o discurso desejado e a prática efetiva, numa coerência das relações humanas recheadas de cuidados.

No caminho que esse artigo traz há evidências do sentido da autonomia com responsabilidades dentro dos fazeres interdisciplinares. Esse movimento é proeminente de uma sociedade que se reafirma criativa, inteligente e capaz de gerir seu próprio destino. $\mathrm{Na}$ tratativa de manter certa coesão textual, a interdisciplinaridade aqui discutida será estudada em duas lentes, são elas: como ritual da ciência e como ciência do ritual. Na primeira lente são valorados os contextos históricos; os pensadores e pensadoras; uma breve descrição sobre a interdisciplinaridade nos estudos da filosofia, da epistemologia, da pedagogia e da sociologia, ou seja, tudo o que pertence ao campo de observação científica cadenciada e elaborada sistematicamente. Cada ritual traduz a história do campo epistemológico da interdisciplinaridade num movimento cronológico centrado na pessoa, o que para os gregos, o cronos age nas descrições e resultados, mantendo a disciplinaridade organizada e coordenada para aprofundar teoricamente os estudos.

$\mathrm{Na}$ segunda lente compreende-se a dimensão existencial humana que dá sentido às evidências científicas mobilizadoras da experiência interdisciplinar. É um exercício de viver o presente em três atos: cuidar de si, do outro e do mundo, ativando a 'escuta sensível' segundo Barbier, filósofo francês, que afirma que

É indispensável lembrar que o homem permanecerá, para sempre, um ser dividido entre o silêncio e a palavra, e que somente a escuta do pesquisador 
poderá penetrar e captar os significados do não-dito. A pessoas que se dispõe a escutar não basta que tenha ouvidos, é necessário que ela realmente silencie sua alma. (BARBIER, 2002, p. I4I)

Nessa lente o tempo kairótico emoldura as práticas demoradamente e extrapola as definições, os objetivos ou os cronogramas préestabelecidos pelas pesquisas cartesianas. O mito de kairós, segundo os gregos, reorganiza outras conexões, outros saltos em territórios disciplinares a serviço da comunicação inter e intrapessoal. É pelas ciências humanas centrada na pessoa que estamos no mundo de forma multidimensional e multifacetado.

Assim, ao recuperar o fluxo inicial da educação formal, onde a pessoa opta por sua profissão, é possível observar que, sob a lente do ritual da ciência, ela registraria cada tempo da sua jornada na busca por resultados rumo ao sucesso profissional, muito parecido às pesquisas concebidas in vitro, sob controle ambiental e das variáveis sobre o objeto estudado. Porém, sob a lente da ciência do ritual, a mesma pessoa vivenciaria cada sentido do seu conhecimento apreendido e ressignificado no meio do processo de autoconhecimento ou de estranhamentos diante dos achados. Em ambos, há certo encantamento.

\section{A INTERDISCIPLINARIDADE COMO RITUAL DA CIÊNCIA}

Ao estudar a interdisciplinaridade como ritual da ciência, não há como suplantar a tradição, a história ou a herança cultural de cada disciplina. Viver a interdisciplinaridade não é dirigir as pessoas com percepções estanques e acabadas sobre o modo como elas aprendem, se desenvolvem ou transformam o mundo, apenas perguntar sobre suas compreensões desse mundo que pede por autorias e responsabilidades. Ela (a interD) não pode ser uma superespecialização ou superciência composta de performances e pirotecnicas pedagógicas. Há que se compreendê-la na humildade, pois o querer cuidar e ser cuidado; escutar e ser escutado; ou educar e ser educado, tornam-se evidências centrais da existência humana que pertence a qualquer cultura. Também nas margens de cada campo disciplinar ou comunicacional há que acolher a aventura da interação e das redescobertas, "a interdisciplinaridade coloca em questão as fronteiras estanques e disciplinares da produção do conhecimento e apela para a necessidade de relações recíprocas entre as disciplinas com vistas a alcançar benefícios mútuos". (PIAGET, 1976)

Como ritual da ciência, a interdisciplinaridade é praticada pelas pessoas na leitura das multiculturas, num misto de dignidade e coerência. Um ritual que recupera a história sem ditar ordens e constructos teóricos para uma legião de pensadores e pesquisadores caminhantes na autonomia, pois, em Japiassu (1976, p.74-75),

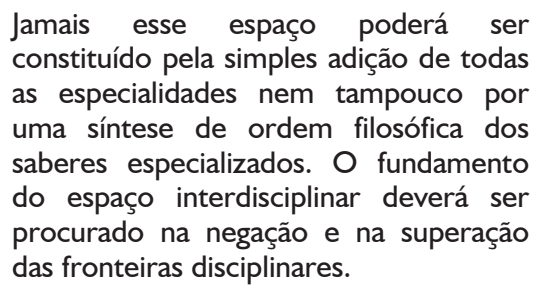

$\mathrm{Na}$ compreensão histórica sobre a interdisciplinaridade, um ritual se efetivou pelas inquietações na arte de educar onde Gusdorf (1960), no final da década anunciava ao mundo os impactos autodestrutivos dos guetos científicos. E Piaget (1976) descreveu a interdisciplinaridade como uma característica presente e inata do ser humano. A partir de 1970, ela foi adotada por pensadores brasileiros como Ivani Fazenda e Hilton Japiassu, culminando no desenho da primeira corrente nacional sobre o saber-fazer interdisciplinar, com foco na prática pedagógica e existencial (pelos estudos da Fazenda) ou com foco na filosofia e na epistemologia (pelos estudos de Japiassu), num marco histórico para os estudos interdisciplinares nas Ciências da Educação.

Cada ritual da ciência propõe uma disposição temporal, cronologicamente disposto, e que busca em cada teoria ou prática certa convergência entre os saberes potencializados nas fronteiras das disciplinas. Nesse ritual as pessoas guardam seus saberes até que sejam 'atiçadas' em novas conexões ou interpretações da vida, pois "a sabedoria é a faculdade que comanda todas as disciplinas pelas quais se aprendem todas as ciências e artes que cobrem a humanidade. " (VICO, 2008, p.49). 
Quadro A - Lentes da Interdisciplinaridade como ritual da ciência.

\begin{tabular}{|c|c|}
\hline No ritual filosófico & Qual a ciência anunciada? \\
\hline Georges Gusdorf, 1960 & $\begin{array}{l}\text { Um movimento que busca desfragmentar o saber } \\
\text { e promover a interação entre pessoas e o mundo. } \\
\text { Denuncia o efeito nocivo do isolamento dos campos } \\
\text { científicos. }\end{array}$ \\
\hline Hilton Japiassu, 1976 & $\begin{array}{l}\text { A InterD acontece pela intensidade das trocas entre } \\
\text { os especialistas e pelo grau de integração real das } \\
\text { disciplinas no interior de um mesmo projeto de } \\
\text { pesquisa }\end{array}$ \\
\hline No ritual epistemológico & Qual a ciência anunciada? \\
\hline Jean Piaget, 1950 & $\begin{array}{l}\text { Ocorre quando há reciprocidade nos intercâmbios } \\
\text { entre as disciplinas e ciências, capaz de gerar } \\
\text { enriquecimento mútuo }\end{array}$ \\
\hline No ritual pedagógico & Qual a ciência anunciada? \\
\hline Ivani Fazenda, 1970 & $\begin{array}{l}\text { É uma perspectiva adotada e profundamente } \\
\text { influenciada pela fenomenologia. O olhar é dirigido } \\
\text { sobre a subjetividade dos sujeitos inseridos no } \\
\text { mundo da vida. Coloca em destaque a questão da } \\
\text { intencionalidade, a necessidade de autoconhecimento } \\
\text { e do diálogo. }\end{array}$ \\
\hline Julie Thompson Klein, 1990 & $\begin{array}{l}\text { A questão da interdisciplinaridade não é antes de } \\
\text { tudo teórica, ela é pragmática e organizacional. Nesse } \\
\text { sentido, ela é de ordem instrumental, operatória e } \\
\text { metodológica. }\end{array}$ \\
\hline No ritual sociológico & Qual a ciência anunciada? \\
\hline Louis Wirtz, 1937 & $\begin{array}{l}\text { Ela implica na existência de um conjunto de disciplinas } \\
\text { interligadas e com relações definidas, que evitam } \\
\text { desenvolver as suas atividades de forma isolada, } \\
\text { dispersa ou fracionada. }\end{array}$ \\
\hline
\end{tabular}

Fonte: Elaboração do autor.

No quadro A alguns pontos de partidas buscam a convergência dos saberes que se fragmentaram excessivamente, e que necessitaram de religações, por isso o cuidado desse texto não se fixar em definições autoexplicativas, e muitas vezes, empobrecidas de sentidos. O que acontece a partir de um estudo sobre a interdisciplinaridade é uma reação frente à abertura do conhecimento na transformação social do mundo mais colaborativo, comunicativo e acolhedor. Acredita-se que não há nada de metafórico ou utópico ao afirmar que esse mundo é desejado por pessoas que se arriscaram noutras ciências ou áreas do saber, e comprovaram que no ineditismo dessas aventuras, a ressignificação do encontro fraterno entre as ciências e as pessoas num deixar-se 'atravessar pela experiência' (BONDIA, 2008).

Esse texto não aponta para as definições sobre a interdisciplinaridade, pois é pela definição que o leitor contata um termo ou um conceito, em contrapartida há um alerta para o risco de aprisionar seus múltiplos sentidos no contexto da pesquisa, da ciência e da vida. 
Como ritual da ciência, a interdisciplinaridade comporta as análises quantitativas frente aos fenômenos naturais, sociais e humanos, e as descreve em seu potencial explicativo e descritivo. Consequentemente, deixa para a posteridade todos os achados em centenas de artigos, textos, dissertações ou teses. Talvez lidos e comentados, ou talvez esquecidos em gavetas e cofres.

\section{A INTERDISCIPLINARIDADE COMO CIÊNCIA DO RITUAL}

A ciência do ritual nasce da presença intencional durante uma ação interdisciplinar, por exemplo, a pessoa será capaz de intervir solidariamente antes de decorar sobre os objetivos teóricos da comunicação não-violenta, ou, mobilizada, ela acolhe as diferenças e os diferentes antes de estudar centenas de slides sobre diversidade cultural, numa organicidade de tempo kairótico, como apreendido no mito grego. Ou ainda, redigir dezenas de páginas sobre o cuidado, ou bem-estar ou sobre a escuta sensível sem, ao menos 'degusta-lo' lentamente, em sabores doces, amargos, salgados ou ácidos, seria um ato fútil. Aprender pela lente da ciência como ritual é trazer a dimensão interdisciplinar que pede o silêncio e a contemplação, já que "a interdisciplinaridade não é aprendida, mas vivida" (FAZENDA, 2009, p.8).

Cada estrato científico desse ritual interdisciplinar carrega as informações sobre o ato de ensinar e dá um colorido vivencial nos intercâmbios entre as disciplinas, e "assim como se diz que o médico produz a saúde no doente graças à intervenção da natureza, do mesmo modo pode-se dizer que um homem produz a ciência num outro homem graças à operação da razão natural, própria deste. A isso se chama ensinar". (GUSDORF, 2003, p. 84)

Sob as lentes que apontam para o ato do cuidado e a experiência da escuta (na ciência do ritual), cabe mencionar um estudo de caso em seus aspectos qualitativos produzidos durante a formação de profissionais da Saúde e da Educação entre os anos de 2014 e 2016 como possibilidade de interação entre a Educação e a Saúde, com foco no autocuidado, o que para Santos, "todo conhecimento é autoconhecimento, e todo desconhecimento é autodesconhecimento" (1990). Nesse período (2014 a 2016) foram realizadas 10 turmas com profissionais docentes e administrativos da Prefeitura Municipal de São Pauloº, dentro do workshop da escuta com aproximadamente 800 participantes, e paralelamente, duas turmas na mesma temática com os profissionais da saúde no curso de pós-graduação em Bases da Medicina Integrativa ${ }^{3}$, com mais de 60 pessoas. Abaixo, o quadro B recupera os cinco rituais presentes em todas as turmas, registrados nos diários de bordos, demonstrando a força de uma prática interdisciplinar em campos formativos aparentemente diferentes, porém irmanados desde suas fundações.

2 Programa de Formação Continuada intitulado Nenhum a Menos da Diretoria Regional de Ensino da Brasilândia e Freguesia do $O$, da rede municipal de São Paulo.

3 Curso lato sensu realizado no Centro de Estudos do Hospital Israelita Albert Einstein, em São Paulo. 
Quadro B - Lentes da Interdisciplinaridade como ciência do ritual

\begin{tabular}{|c|c|}
\hline A ciência do & Qual o ritual praticado? \\
\hline Autocuidado & $\begin{array}{l}\text { Nas rodas de prosas onde as pessoas se expressavam abertamente e } \\
\text { com respeito, surge a narrativa de um aluno médico: "A cidade não } \\
\text { para. O barulho não para. O silêncio é difícil. Se desconectar é difícil. } \\
\text { O pouco de serenidade presente ali me traz uma enorme vontade de } \\
\text { dormir..." (2014) }\end{array}$ \\
\hline A ciência da & Qual o ritual praticado? \\
\hline Escuta & $\begin{array}{l}\text { Nos ciclos da escuta em espaços externos além-muros da escola, } \\
\text { são registradas as sensações dos participantes. Narrativa de uma } \\
\text { aluna da área da saúde: "Fiquei em silêncio enquanto uma criança } \\
\text { visitava seu amiguinho na UTI Infantil. Lembrei-me do processo de } \\
\text { escuta e deixei que o pequeno visitante compreendesse o momento } \\
\text { de doença e morte iminente pela qual passava o seu amigo. E ele } \\
\text { compreendeu sem que eu o tivesse orientado numa comunicação } \\
\text { médica convencional" (2015) }\end{array}$ \\
\hline A ciência da & Qual o ritual praticado? \\
\hline Comunicação & $\begin{array}{l}\text { Diante dos registros escritos, falados e imagéticos para a comunicação } \\
\text { eficaz dos participantes, nasce a narrativa de um professor do Ensino } \\
\text { Fundamental: "Quando me olho em muito não me percebo, o outro } \\
\text { me invade, me confunde, me domina. Às vezes, "eu" não existo, e } \\
\text { outras vezes "eu" nunca, de fato, existi". (2015) }\end{array}$ \\
\hline A ciência do & Qual o ritual praticado? \\
\hline Bem-estar & $\begin{array}{l}\text { Vivências de bem-estar onde as pessoas desenvolvem a auto-crítica } \\
\text { sobre sua qualidade de vida e formação, a narrativa de uma aluna } \\
\text { professora de Educação Infantil: "O que fiz pensando em cuidar } \\
\text { de mim? Tentei dormir mais, me alimentar melhor, dar mais amor } \\
\text { e receber amor. Por vezes escorreguei, e me reergui, lembrando } \\
\text { sim que precisava cuidar de mim. Lembrei-me também que } \\
\text { precisava desabafar, falar e colocar para fora palavras que estavam } \\
\text { incomodando. Curei meus desafetos" (2014) }\end{array}$ \\
\hline A ciência do & Qual o ritual praticado? \\
\hline Reconhecimento & $\begin{array}{l}\text { Na arte de reconhecer nossa capacidade inata de cuidado e limites, } \\
\text { surge uma narrativa de um aluno da área da saúde: "Estou agora em } \\
\text { um local escuro, atrás de uma árvore na entrada do parque. Penso } \\
\text { que aqui representa a nossa sombra, nosso lado escuro, nossos medos } \\
\text { em nossas formas distorcidas de compreensão da verdade." (2016) }\end{array}$ \\
\hline
\end{tabular}

Fonte: Elaboração do autor.

Dessas práticas interdisciplinares que aproximam a Saúde da Educação é que foram evidenciados os desejos e as confianças que pedem diferentes conexões na crise da escuta pela qual atravessamos. Observou-se nesse estudo de caso que as pessoas se apressam num eterno porvir e mobilizados por aquilo que ainda desconhecem. Elas se distanciam da potência criativa e inovadora do presente, que, como o próprio nome diz, as presenteia. A pressa 
tende a 'lançá-las' em atitudes de ansiedades e de estresses diante de cenários hipotéticos. É preciso reverenciar a simplicidade da ação interdisciplinar no sentido do autocuidado, da escuta, da comunicação, do bem-estar e do reconhecimento pela comunicação assertiva e intencional que trate o ciclo de confiança mútua em infinitas combinações e paradoxos.

Evidenciou-se nessas ciências que o ritual da escuta não é mera prostração ou isolamento diante da vida, mas a ativação da força inata que nos faz compreender que toda a palavra tem efeito de intervenção e tende a desfocar a realidade, carregando um alto grau de intencionalidades. Quando se fala, traz-se um encadeamento de ideias e ideologias criando um abismo comunicacional entre o ouvinte e o falante. Escutar é mais do que ouvir, cuidar é mais do que dirigir pessoas rumo ao estabelecimento dos diferentes vínculos humanos. Por isso, ao vivenciar um percurso formativo em qualquer campo do saber, as reverências ao conhecimento trazido pelo outro, numa relação comunicativasutil, estabelecem novos questionamentos vitais: Por que existem hierarquias entre as disciplinas ao ponto de desconsiderar o que cada uma traz de precioso? Como entender que a ciência do ritual é um complemento ao ritual da ciência?

Do ponto de vista integrador, a
interdisciplinaridade requer equilíbrio
entre amplitude, profundidade e
síntese. A amplitude assegura uma larga
base de conhecimento e informação.
A profundidade assegura o requisito
disciplinar e/ou conhecimento e
informação interdisciplinar para a tarefa
a ser executada. A síntese assegura o
processo integrador. (JAPIASSU, 1976,
p. 65-66)

Um processo integrador pede o equilíbrio entre a informação, a didática e as ciências, bem como na profundidade da crítica ao excesso da produtividade, da competitividade, das meritocracias ou dos gerenciamentos, numa amplitude à invasão as escolas ou as ciências dessa dinâmica fragmentária dos saberes.

Em cada diário de bordo com os registros de todos os participantes do workshop da escuta, a religação dos saberes esteve presente pelo encontro fraterno e interdisciplinar, o que reforça a dinâmica existencial segundo Bachelard, "toda pessoa deveria então falar de suas estradas, de suas encruzilhadas, de seus bancos. Toda pessoa deveria fazer o cadastro de seus campos perdidos" (2005, p. 31). Encontrar-se com o outro suspendendo os pré-julgamentos nos oportunizaria à compreensão humana como uma ciência do ritual. O diálogo aberto com áreas distintas pela prática interdisciplinar dá sentido ao aprender para além do decorar, pois "os anos de estudos passam e são esquecidas a regra de três, as datas da história e a classificação dos vertebrados. O que fica para sempre é a lenta e difícil tomada de consciência de uma personalidade" (GUSDORF, 2003, p. 41).

\section{CONCLUSÃO}

Tanto pela lente do ritual da ciência ou pela lente da ciência do ritual, a interdisciplinaridade chama pelo diálogo aberto e franco que se encontra nas fronteiras das disciplinas para o pensamento livre, à ação acolhedora e a escuta sensível. Desde o contexto histórico com os pensadores ou pesquisadores das ciências e da interdisciplinaridade até a experiência relatada na cidade de São Paulo como um caminho possível, não há como retroceder na convergência entre setores que se encontram isolados em seus dogmas e convenções. Para que a complexidade existente nas relações humanas e sociais sejam adequadamente interpretadas e solucionadas para a boa convivência, a interdisciplinaridade subsidiaria a abordagem comunicacional capaz de efetivar essas vontades transitórias.

Nas duas lentes, os estudos passam de uma metodologia disciplinar e uma epistemologia positivista para uma metodologia interativa e uma epistemologia interdisciplinar, entrelaçando as histórias de vida num movimento humanizado e humanizante. É nessa dinâmica vital que as percepções e ferramentas pelo olhar da educação e da formação são carregados de paixões e (re) descobertas. Encontrar-se ganha um novo sentido de comunhão e colaboração.

As ciências podem ser dinamizadas e 'oxigenadas' pela abordagem interdisciplinar cientificamente posta no intuito de amenizar as incompreensões e isolamentos humanos. É um ato de comunicar para aproximar as pessoas e as suas histórias. Ciências e rituais que agregam os campos prático, filosófico, político, pedagógico ou social numa educação-próxima-de-nós, quase familiar. 
Artigo recebido em 20/0 I/20I 7 e aceito para publicação em 09/02/20I 7

\section{STUDIES ON INTERDISCIPLINARITY: ritual of science or science of the ritual?}

ABSTRACT A long time ago, interdisciplinarity has appeared as a force for scientific research, pedagogical or corporate practices, as well as stamping undergraduate and graduate degrees in Brazil and in the world, but it a concept has multiple meanings and meanings beyond their own definitions. In fact, defining interdisciplinarity can impoverish its function of openness to knowledge, science and information in a society that has complexity as a master identity. Also to dissect it in a sentence or paradigm is to leave the concept of laboratory size that would allow researchers to manipulate their variables. That is why the present work has the form of study that includes the historical multiplicities that make Interdisciplinarity an act of care and an experience of listening between people and the world in a core-education, almost familiar. As a result, some common themes presented in the trainings with the professionals of Education and Health carried out between the periods of 2014 to 2016, in the city of São Paulo, and that legitimized the autonomy between the pedagogical make and feel in the development of people for the collective and collaborative.

Key words: $\quad$ complexity; ritual of science; science of ritual; interdisciplinarity; sensitive listen

\section{REFERÊNCIAS}

BACHELARD, Gaston. A Poética do Espaço. Editora Martins Fontes, São Paulo, 2005.

BHABHA, Homi K. O local da cultura. $1^{\text {a }}$ reimpressão. Belo Horizonte: UFMG, 2001

BARBIER, Rene. Escuta sensível na formação de profissionais da saúde. Ver em http:/ / www. barbier-rd.nom.fr/ESCUTASENSIVEL.PDF Acessado em 15/01/2017

A escuta sensível na abordagem transversal. In: BARBOSA, J. (coord). Multirreferencialidade nas ciências e na educação. São Carlos: Editora da UFSCar, 1998, p. 168-99.

A pesquisa-ação. Trad. Lucie Didio. Brasília: Plano Editora, 2002.

BONDIA, Jorge Larossa. Notas da experiência e o saber da experiência. Unicamp, Jan/Fer/Mar/ Abr 2002, no 19. Acessado em 03/01/2017

CERQUEIRA, Teresa C. S. (org). (Con) Textos em Escuta Sensível. Brasília: Thesaurus, 2011.
FAZENDA, Ivani Catarina Arantes. Didática e Interdisciplinaridade. Editora Papirus, São Paulo, 2006.

Práticas Interdisciplinares na Escola. Editora Cortez, São Paulo, 1993.

FAZENDA, Ivani C. Arantes; SOUZA, Fernando Cesar. Diálogos interdisciplinares em Saúde e Educação: a arte do cuidar. Revista Educação \& Realidade, v. 37, n.1, jan./abr. 2012

FOUCAULT, Michel. Microfísica do Poder. Editora Graal, São Paulo, 1979.

O governo de si e dos outros. Editora Martins Fontes, São Paulo, 2010.

FREINET, Célestin. Pedagogia do Bom Senso. São Paulo: Martins Fontes, 2004.

FREIRE, Paulo. Pedagogia da autonomia: saberes necessários à prática educativa. 39. Ed. São Paulo: Paz e Terra, 1996.

GUSDORF, Georges. Professores para quê? Para uma pedagogia da pedagogia. Trad. MF. $3^{\mathrm{a}} \mathrm{ed}$. São Paulo: Martins Fontes, 2003. 
JAPIASSU, Hilton. Interdisciplinaridade e a patologia do saber. Editora Imago, São Paulo, 1976.

NATURE, Revista. INTERDISCIPLINARITY. In volume 525, number 7569, september 2005.

PACHECO, José. Pequeno dicionário das utopias da educação. Rio de Janeiro: Wak Editora,2009.

POMBO, O. Antologia: Interdisciplinaridade, Humanismo, Universidade. Porto: Editora Campo das Letras, 2004.

MORIN, Edgar. Os sete saberes necessários à educação do futuro. São Paulo, Cortez, 2001
REVISTA INTERCOM. Graig Calhoun. RBCC, São Paulo, v.35, n.1, p.277-310, jan/jun. 2012.

RICOEUR, Paul. Percurso do Reconhecimento. São Paulo, Edições Loyola, 2006

RINALDI, Carla. Diálogos com Reggio Emilia. São Paulo, Editora paz e Terra, 2012

CONFERÊNCIA GERAL DA UNESCO. Declaração de Princípios sobre a Tolerância. Paris: UNESCO, 1995.

VICO, Giambattista. Ciência Nova. São Paulo: Icone Editora, $1^{\text {a }}$ versão, 2008. 